\title{
MOLECULAR DOCKING STUDIES ON THE THERAPEUTIC TARGETS OF ALZHEIMER'S DISEASE (AChE AND BChE) USING NATURAL BIOACTIVE ALKALOIDS
}

\author{
PUNABAKA JYOTHI, KUNA YELLAMMA* \\ Department of Zoology, Sri Venkateswara University, Tirupati, Andhra Pradesh, India \\ Email: Yellamma55@gmail.com
}

Received: 23 Aug 2016 Revised and Accepted: 05 0ct 2016 \begin{abstract}
Objective: Alzheimer's disease (AD), a progressive neurodegenerative disorder with many cognitive and neuropsychiatric symptoms, is biochemically characterized by a significant decrease in the brain neurotransmitter Acetylcholine (ACh)

Methods: In the present insilico study, six plant bioactive compounds namely Harmol, Vasicine, Harmaline, Harmine, Harmane and Harmalol (from $P$. Nigellastrum Bunge) were analyzed for their inhibitory role on AChE (Acetylcholinesterase) and BChE (Butyrylcholinesterase) activity by applying the molecular docking studies. Other parameters viz. determination of molecular interaction-based binding affinity values, protein-ligand interactions, Lipinski rule of five, functional properties and biological activities for the above compounds were also calculated by employing the
\end{abstract} appropriate bioinformatics tools.

Results: The results of docking analysis clearly showed that Harmalol has highest binding affinity with AChE (-8.6 kcal/mole) and BChE (-8.0 $\mathrm{kcal} / \mathrm{mole}$ ) but it does not qualified the enzyme inhibitory activity, since it was exerted, and also has least percentage activity on AD and neurodegenerative disease. Whereas, the Harmine has been second qualified binding affinity (-8.4 kcal/mol) and first in other parameters when compared with Harmalol.

Conclusion: Based on docking results and other parameters conducted, we are concluding that Harmine is the best compound for further studies to treat AD.

Keywords: Alzheimer's disease (AD), Acetylcholinesterase, Butyrylcholinesterase, Lead Molecules

(C) 2016 The Authors. Published by Innovare Academic Sciences Pvt Ltd. This is an open access article under the CC BY license (http://creativecommons.org/licenses/by/4. 0/J DOI: http://dx.doi.org/10.22159/ijpps.2016v8i12.14833

\section{INTRODUCTION}

Alzheimer's disease (AD) is due to progressive neuronal loss of cognitive function, is seen in aging people and indicative of commonest cause of dementia. The risk percentage of AD is rising gradually throughout worldwide. As per the recent WHO reports 20 million people are in advanced stage of AD [1, 2]. Acetylcholine, a neurotransmitter released by nerve cells acts as a signal intermediate between two nerve cells. Pathological character of acetylcholine depletion in the brain is due to increased levels of Acetycholinesterase (AChE), an enzyme that catalyzes acetylcholine hydrolysis. Another therapeutic target of $\mathrm{AD}$ viz. the Butyrylcholinesterase (BChE) also shows significantly more than $50 \%$ sequence similarity with AChE [3]. Moreover, the function and location of $\mathrm{BChE}$ is very similar to Acetycholinesterase. These two therapeutic targets of $\mathrm{AD}$ are essential for termination of nerve impulse transmissions at cholinergic synapses by rapid hydrolysis of acetylcholine and this can be counteracted by using therapeutically and biologically active compounds.

As per the cholinergic hypothesis, AChE and BChE hydrolytic enzymes detected in neurofibrillary tangles and neuritic plaques in the brain act on ACh and Butyrylcholine to terminate its actions in the synaptic cleft by cleaving the neurotransmitter to choline and acetate. It was suggested that AChE predominated in the healthy brain, whereas BChE considered playing a minor role in regulating brain ACh levels. However, BChE activity progressively increases in patients with $A D$, while AChE activity remains unchanged or declines.

Pharmaceutical companies, though very much interested in wellestablished pharmacology and chemistry based drug discovery approaches, are facing various complications in finding novel drugs [4]. Now-a-days, the pharmaceutical companies make huge investments for development of new drugs. At this juncture, Bioinformatics has emerged into pharmacology to fulfil the aspiration of pharmacologists to generate several potential drugs in short period with low risk [5]. The major application is computeraided drug design, in which structure-based drug design (SBDD) plays a very important role in identification of new drugs against the selected therapeutic targets. SBDD requires knowledge on biological therapeutic target, aims to discover small molecules (ligands) with desired chemical or drug properties. This approach provides an idea regarding interaction of target and ligands by creating biological environment computationally [6].

Genus Peganum (Zygophyllaceae) has six species native to the central Asia region, but now they grows wild and discontinuously in Africa, the Middle East, India, South America, Mexico, and southern US. Nigellastrum Bunge is a plant belongs to genus peganum, has many advantageous medicinal properties. Recent reports are evidenced that this plant has rich source of alkaloids, are used to treat neurodegenerative diseases. Vasicine, Harmaline, Harmalol Harmane, Harmine and Harmol are $\beta$-carboline and quinoline alkaloids isolated from this plant and evaluated its anticholinesterase properties in invitro experiments. But best of our knowledge, at present there is no evidence for molecular interactions of these compounds with AChE and BChE proteins. The aim of the present study to perform docking studies on AChE and $\mathrm{BChE}$ therapeutic targets using these selected natural alkaloids for knowing binding affinities and molecular interactions.

\section{MATERIALS AND METHODS}

Selection of ligands and preparation of therapeutic target proteins

The lead compounds were collected from an article published by Ting Zhao and his co-workers (2013) [7]. The compounds were selected from $\beta$-carboline and quinoline alkaloids derivatives from the genus Peganum, especially from the P. Nigellastrum Bunge plant which includes Vasicine, Harmaline, Harmalol, Harmane, Harmine and Harmol. All these structures were downloaded from pubchem database with possible structure definition file format for docking 
studies. The subsequent docking macro molecules viz. AChE and $\mathrm{BChE}$ were downloaded from protein databank (PDB) [8]. The AChE protein in PDB databank has an ID 5FPQ: structure of homo sapiens acetyl cholinesterase phosphorylated by sarin [9]. Whereas, the BChE has an ID 2Y1K: structure of human butyrylcholinesterase inhibited by CBDP (12h soak): phosphoserine adduct [10]. The protein structures included hetero atoms and its inhibitors were removed in an Argus lab tool. Hetero atom's and inhibitors free protein structures were subjected to energy minimization using Swiss pdb viewer [11].

\section{Molecular docking studies}

Molecular docking studies on the above mentioned selected compounds against $\mathrm{AChE}$ and $\mathrm{BChE}$ was done in auto dock vina in PyRx software, which is freely accessible and designed for molecular docking studies. PyRx includes docking wizard with an easy-to-use user interface which makes it a valuable tool for computer-aided drug design. PyRx also includes chemical spreadsheet-like functionality and powerful visualization engine that are essential for rational drug design [12]. The selected drug targets were energy minimized, and converted them into pdbqt format in PyRx.

\section{Molecular interactions visualization}

Auto dock vina generated docking pair of protein and ligands was saved in pdb format, and were visualized in PyMOL [13] visualization tool i.e. python-enhanced molecular graphics tool. It excels at three-dimensional visualization of proteins, small molecules, density, surfaces and trajectories. It also includes molecular editing, ray tracing, and movies. The ligand binding sites and surrounding amino acids of ligands were also visualized. Molecular interactions in the form of hydrogen bonds between proteins and ligands were characterized and the distance of hydrogen bonds was also calculated.

\section{Active site prediction}

Proteins have specific sites, the amino acid residue side chains that form an active cavity or cleft where the ligands or atoms or other proteins are capable to bind and are called active sites. The active sites of the AChE and BChE proteins were identified by using supercomputing facility for bioinformatics and computational biology, IIT Delhi. Identified active sites were visualized in PyMOL molecular visualization tool.

\section{Prediction of drug properties}

Predictions of drug properties were calculated in Molinspiration, a chemo informatics tool. It calculates lipinski rule of five (rule of five), a key to evaluate drug likeness or determine the chemical compounds pharmacological and biological properties, which concur with the oral prescription drugs for human [14]. The rule of five values includes cLog P, molecular weight, hydrogen bond donors and hydrogen bond acceptor for the drugs. Further, we predicted compounds activity on biological targets (GPCR ligand, ion channel modulator, kinase inhibitor, nuclear receptor ligand, protease inhibitor, and enzyme inhibitor) involved in AD by using Molinspiration tool.

\section{PASS prediction}

The functions of the compounds with structural features are essential in the drug discovery area because isolated or identified new compounds are needed to aim correct therapeutic diseases especially therapeutic targets. The PASS (prediction of activity spectra for substances) is an online software tool, which predict more than 300 pharmacological effects and biochemical mechanisms based on structural information of interested compound and also predict the its biological target [15]. PASS predicts the pi (probability of inactivity) and pa (probability of activity) values. In this study, we performed the pass prediction for all the selected alkaloids, which could therapeutically inhibit the AChE and BChE.

\section{RESULTS AND DISCUSSION}

Several reviews on the newly discovered AChE inhibitors obtained from plants, fungus and marine organisms have also been reported over the last years [16-18]. The majority of these AChE inhibitors belong to the alkaloid group, including indole, isoquinoline, quinolizidine, piperidine and steroidal alkaloids. Alkaloids $\alpha$ chaconine, $\alpha$-solanine, tomatine, berberine, palmatine and jatrorrhizine are other metabolites that inhibit AChE and BChE [1921]. In this study, we performed docking studies in between six selected plant bioactive alkaloid compounds against the cholinergic enzyme's viz. AChE and BChE active sites.

Docking interaction results of AChE are represented in table 1. Harmalol has shown two hydrogen bond interactions with Tyr130 and Trp 84 by means of $-8.6 \mathrm{kcal} / \mathrm{mol}$ binding affinity. Harmane has shown one hydrogen bond interaction with Asp72 when it was fit into active site at -8.4 binding affinity. Harmaline and Harmine have shown single hydrogen bond interaction with Glu199 amino acid with -8.2 and $-8.4 \mathrm{kcal} / \mathrm{mol}$ binding affinity respectively. Harmol has $-8.2 \mathrm{kcal} / \mathrm{mol}$ binding affinity and four hydrogen bond interactions with the active site of AChE. The drug atoms formed hydrogen bond interaction with Tyr121, GLY199, SER200 and ASP72 amino acids present in an active site. Vasicine not showed any hydrogen bond interactions with active site amino acids with binding affinity -8.1 $\mathrm{kcal} / \mathrm{mol}$. The least binding affinity (more negative value) of the compounds is considered as best drugs in pharmaceutics. The molecular visualization of molecular docking poses of alkaloids in active site of AChE is represented in fig. 1. It clearly showed that the bioactive alkaloids all are interacted and situated at the same an active site of AChE.

The docking interactions of alkaloids with BChE protein was represented in table 1 and fig. 1. Harmalol showed single bond interaction with Glu197 and $-8.0 \mathrm{kcal} / \mathrm{mol}$ binding affinity in an active site of BChE. Harmine also showed single hydrogen bond interaction with Tyr322 by the result of $-7.8 \mathrm{kcal} / \mathrm{mol}$. Harmane actively bound to $\mathrm{BChE}$ by affinity of- $7.9 \mathrm{kcal} / \mathrm{mol}$ and interacted with Gly115 amino acid. Harmol interacted with BChE with-7.8 $\mathrm{kcal} / \mathrm{mol}$; GLU197 amino acid of the active site showed hydrogen bonding with drug Harmol. $-7.8 \mathrm{kcal} / \mathrm{mol}$ binding affinity has observed between Vasicine and BChE active site, Ser198 has formed two hydrogen bond interactions. Harmaline also showed same binding affinity as Vasicine but it has two hydrogen bond interactions with Tyr128 and Gly115 of protein. Harmine was virtually bound to active site by pairing one hydrogen bond to Gly115 and binding affinity was $-7.9 \mathrm{kcal} / \mathrm{mol}$. docking results of BChE also clearly showed that all compounds have shown good binding affinity with active site and docked at the same an active site. Overally, in sense of binding affinities of compounds with target proteins are revealed that each compound has highest score with $\mathrm{AChE}$ than BChE because of AChE has a more developed peripheral anionic site and narrower aromatic gorge than $\mathrm{BChE}$ [22].
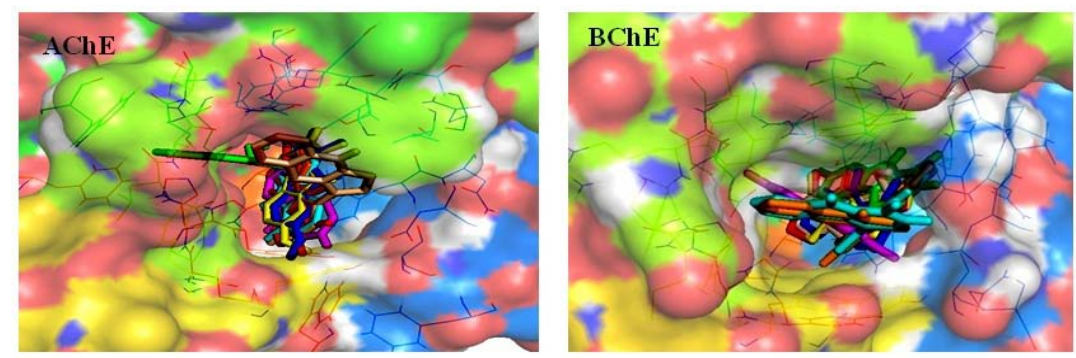

Fig. 1: Binding of alkaloids in active site of AChE and BChE. The alkaloids are represented in stick format 
Identification of drug interactive atoms with specific amino acid residues of therapeutic target have played an important role in drug discovery and function identification of proteins using mutational studies. Insilico understanding of drug interactions with active site amino acid residues of target protein has given a solution to scientists for inhibition of targets [23]. In an identification process of AChE and BChE active site key amino acid residues, we found that the amino acids such as Tyr70, Asp72, TRP84, Tyr121, Tyr130,
Glu199 and Ser200 are in AChE and the key amino acids of BChE which are involved in the alkaloids interaction are Gly115, Tyr128, Glu197, Ser198 and Tyr332. Most of the compounds we docked were bounded at same active site but their interaction with amino acids was different. This difference in interaction is purely dependent on the structures of the compounds and rotatable bonds present. The 2 dimensional (2D) structures of plant bioactive alkaloids are shown in fig. 2 .

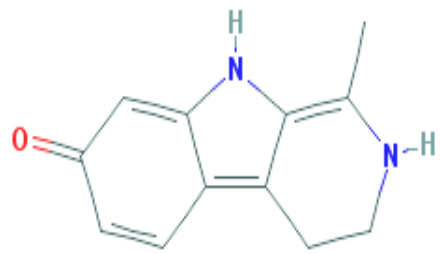

Harmolol

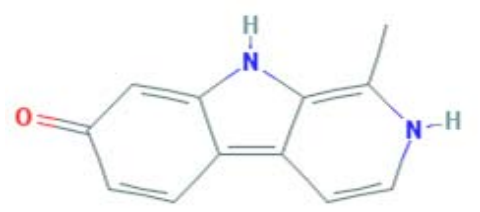

Harmol

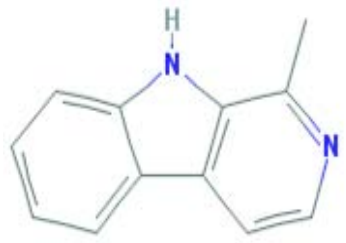

Harmane

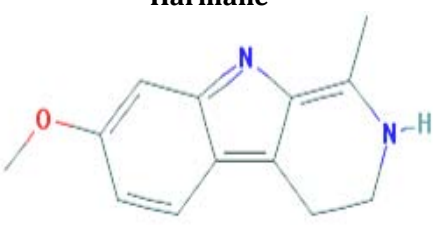

Harmaline<smiles>COc1ccc2c(c1)[nH]c1c(C)nccc12</smiles>

Harmine<smiles>O[C@H]1CCN2Cc3ccccc3N=C12</smiles>

Vasicine

Fig. 2: Chemical structures of alkaloids

Structural genomics pays attention in providing a number of structures but it does not give enough functional annotations of proteins. In order to obtain a function of proteins based on structure not from sequence, the computational tools are successful. It investigates and identifies the functional sites of protein based on structure. In case of non-enzymes those sites are called functionally importance regions whereas in enzymes they are called as active sites [24]. We predicted active sites of AChE and BChE enzymes (fig. 3).
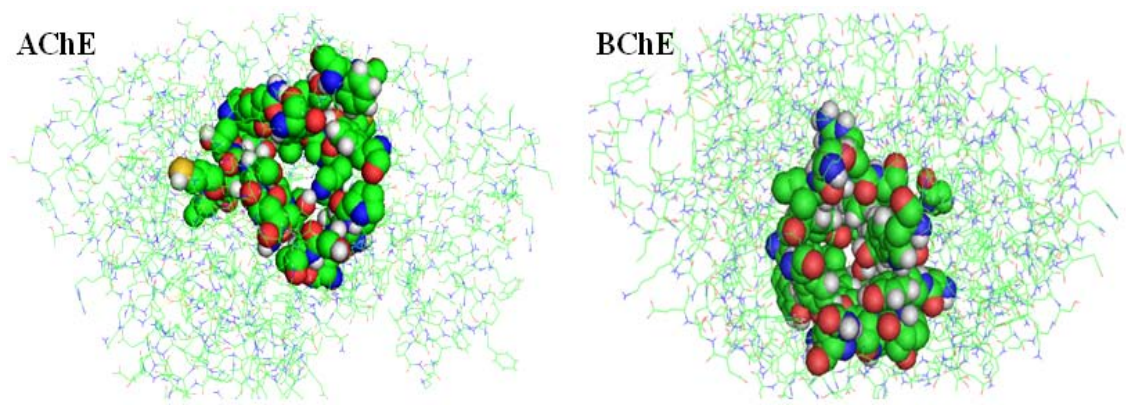

Fig. 3: The active site amino acids of the AChE and BChE, amino acids are represented in spheres

Table 1: The binding interactions of AChE (Left) and BChE (right)

\begin{tabular}{|c|c|c|c|c|c|c|c|c|c|}
\hline \multirow{3}{*}{$\begin{array}{l}\text { S. } \\
\text { No. }\end{array}$} & \multirow{3}{*}{$\begin{array}{l}\text { Compound } \\
\text { name }\end{array}$} & \multicolumn{4}{|c|}{ Alkaloids binding interactions with AChE } & \multicolumn{4}{|c|}{ Alkaloids binding interactions with BChE } \\
\hline & & $\begin{array}{l}\text { Hydrogen } \\
\text { bond }\end{array}$ & $\begin{array}{l}\text { Amino } \\
\text { acid }\end{array}$ & Distance & $\begin{array}{l}\text { Binding } \\
\text { Affinity }\end{array}$ & $\begin{array}{l}\text { Hydrogen } \\
\text { bond }\end{array}$ & $\begin{array}{l}\text { Amino } \\
\text { acid }\end{array}$ & Distance & $\begin{array}{l}\text { Binding } \\
\text { Affinity }\end{array}$ \\
\hline & & $\begin{array}{l}\text { Protein---- } \\
\text { ligand }\end{array}$ & & & & $\begin{array}{l}\text { Protein---- } \\
\text { ligand }\end{array}$ & & & \\
\hline \multirow[t]{2}{*}{1} & Harmolol & H--------------O & Tyr130 & 2.5 & -8.6 & O--------------0 & Glu197 & 3.1 & -8 \\
\hline & & O------------H & Trp84 & 2.5 & & & & & \\
\hline 2 & Harmine & 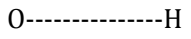 & Glu199 & 2.2 & -8.4 & O-----------H & Gly115 & 2.2 & -7.9 \\
\hline 3 & Harmane & 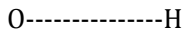 & Asp72 & 2.4 & -8.4 & 0--------------H & Tyr332 & 2.3 & -7.8 \\
\hline \multirow[t]{4}{*}{4} & Harmol & O------------H & Tyr121 & 2.5 & -8.2 & 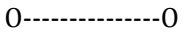 & Glu197 & 3.4 & -7.8 \\
\hline & & H------------O & Glu199 & 2.6 & & & & & \\
\hline & & H-------------O & Ser200 & 2.4 & & & & & \\
\hline & & 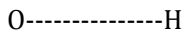 & Asp72 & 2.2 & & & & & \\
\hline \multirow[t]{2}{*}{5} & Harmaline & 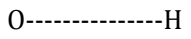 & Glu199 & 2.1 & -8.2 & 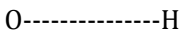 & Tyr128 & 2.8 & -7.8 \\
\hline & & & & & & 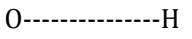 & Gly115 & 2.3 & \\
\hline \multirow[t]{2}{*}{6} & Vasicine & No interaction & & & -8.1 & H--------------O & Ser198 & 2.8 & -7.8 \\
\hline & & & & & & O--------------H & Ser198 & 1.9 & \\
\hline
\end{tabular}


Table 2: Prediction of bioactivity and Lipinski rule of five for bioactive alkaloids

\begin{tabular}{|c|c|c|c|c|c|c|c|c|c|c|c|}
\hline \multirow{2}{*}{$\begin{array}{l}\text { S. } \\
\text { No. }\end{array}$} & \multirow{2}{*}{$\begin{array}{l}\text { Compound } \\
\text { name }\end{array}$} & \multicolumn{6}{|c|}{ Bio activity } & \multicolumn{4}{|c|}{ Lipinski rule of five } \\
\hline & & $\begin{array}{l}\text { GPCR } \\
\text { ligand }\end{array}$ & $\begin{array}{l}\text { Ion channel } \\
\text { modulator }\end{array}$ & $\begin{array}{l}\text { Kinase } \\
\text { inhibitor }\end{array}$ & $\begin{array}{l}\text { Nuclear } \\
\text { receptor } \\
\text { ligand }\end{array}$ & $\begin{array}{l}\text { Protease } \\
\text { inhibitor }\end{array}$ & $\begin{array}{l}\text { Enzyme } \\
\text { inhibitor }\end{array}$ & $\begin{array}{l}\text { Mi } \\
\text { LogP }\end{array}$ & MW & nON & nOHNH \\
\hline 1 & Harmalol & -0.94 & -0.88 & -0.75 & -1.37 & -1.35 & -0.61 & 1.77 & 200.24 & 3 & 2 \\
\hline 2 & Harmane & -0.24 & 0.40 & 0.19 & -0.72 & -0.81 & 0.14 & 2.59 & 182.23 & 2 & 1 \\
\hline 3 & Harmine & -0.16 & 0.30 & 0.31 & -0.46 & -0.68 & 0.16 & 2.63 & 212.25 & 3 & 1 \\
\hline 4 & Harmol & -0.52 & 0.33 & 0.11 & -0.77 & -0.93 & 0.11 & 1.89 & 198.22 & 3 & 2 \\
\hline 5 & Harmaline & -0.64 & -0.71 & -0.63 & -1.06 & -1.12 & -0.53 & 2.50 & 214.27 & 3 & 1 \\
\hline 6 & Vasicine & 0.03 & 0.32 & -0.43 & -0.5 & -0.36 & 0.24 & 1.04 & 188.23 & 3 & 1 \\
\hline
\end{tabular}

GPCR: G Protein Couple Receptor; MW: Molecular Weight; nON: Hydrogen Bond Acceptor; nOHNH: Hydrogen Bond Donor.

Prediction of drug likeness properties for alkaloids in the form of lipinski rule of five revealed that all the selected alkaloids had obeyed the rules. Also, the biological activities of the compounds on different common targets are shown in table 2. The compounds such as Harmol, Vasicine, Harmine and Harmane have an enzyme inhibitory activity, while Harmaline, Harmalol have no enzyme inhibitory property. Analysis of our PASS prediction for plant alkaloid has revealed that, Harmine is used to treat Neurodegenerative diseases, it stimulates the acetylcholine release and structurally elevated function for the treatment of AD (table 3).

Table 3: Data generated for selected ligand to predict the biological activity through PASS

\begin{tabular}{|c|c|c|c|}
\hline S. No. & Activity & Pa & $\mathbf{P i}$ \\
\hline 1 & Acetylcholine neuromuscular blocking agent & 0,111 & 0,443 \\
\hline 2 & Antiinflammatory and ophthalmic & 0,058 & 0,316 \\
\hline 3 & GABA receptor agonist & 0,223 & 0,223 \\
\hline 4 & Neurodegenerative diseases treatment & 0,139 & 0,296 \\
\hline 5 & Acetylgalactosaminyl-0-glycosyl-glycoprotein beta-1,3-N-acetylglucosaminyltransferase inhibitor & 0,179 & 0,278 \\
\hline 6 & Free radical scavenger & 0,088 & 0,187 \\
\hline 7 & NOS2 expression inhibitor & 0,110 & 0,209 \\
\hline 8 & Acetylcholine release stimulant & 0,030 & 0,124 \\
\hline 9 & Mood disorders treatment & 0,113 & 0,198 \\
\hline 10 & Anti parkinsonian, tremor relieving & 0,089 & 0,173 \\
\hline 11 & Acetyl-CoA transferase 2 inhibitor & 0,025 & 0,043 \\
\hline 12 & Acetylcholine M3 receptor agonist & 0,062 & 0,048 \\
\hline
\end{tabular}

On the whole, even though our docking results showed Harmalol has highest binding affinity with both targets, it did not exert inhibitory activity on the target enzymes and moreover has least activity on neurodegenerative disease AD. However, when we look at the docking results, Harmine has occupied second position with highest binding affinity for both AChE and BChE. The enzyme inhibitory activity is predicted in Molinspiration analysis and the neurodegenerative disease and alzheimer's disease treatment is explored from structurally determined functional properties using PASS

\section{CONCLUSION}

Based on Insilco docking interaction and binding affinity studies, all the alkaloids have exhibited good binding affinity with the cholinergic enzymes AChE and BChE, the key therapeutic targets of AD. However, Harmine has been qualified all predicted drug property parameters, and also has second highest binding affinity score with targets. So, Harmine compound is confirmed as the best to inhibit both AChE and BChE targets to treat AD.

\section{ACKNOWLEDGEMENT}

I thank the UGC, New Delhi for providing necessary support by awarding RGNF for my research work. I also thank the Co-ordinator, DBT-supported Bioinformatics Infrastructure Facility, Department of Zoology, Sri Venkateswara University, Tirupati for providing computer lab facilities to carry out this research work.

\section{CONFLICT OF INTERESTS}

All authors are declared, there is no conflict of interest

\section{REFERENCES}

1. Tsalkovich L, Sallon S, Paavilainen H, Rosenmann H. Antialzheimer's disease related activities of israeli medicinal plants. JSM Alzheimer's Dis Related Dementia 2015;2:1015-22.
2. Chandra MP, Venkateshwar R. Biological evaluation of schiff bases of new isatin derivatives for anti-Alzheimer's activity. Asian J Pharm Clin Res 2014;7:114-7.

3. Miroslav P. Cholinesterases, a target of pharmacology and toxicology. Biomed Pap Med Fac Univ Palacky Olomouc Czech Repub 2011;155:219-30.

4. Iskar M, Zeller G, Zhao XM, van NV, Bork P. Drug discovery in the age of systems biology: the rise of computational approaches for data integration. Curr Opin Biotechnol 2012;23:609-16.

5. Ortega SS, Cara LC, Salvador MK. In silico pharmacology for a multidisciplinary drug discovery process. Drug Metabol Drug Interact 2012;27:199-207.

6. Lu C, John KM, Hoang TT, Sharangdhar SP, Lei DC, Shuxing Z. From laptop to benchtop to bedside: structure-based drug design on protein targets. Curr Pharm Design 2012;18:1217-39.

7. Ting Zhao, Ke-min D, Lei Z, Xue-mei C, Chang-hong W, Zhengtao W. Acetylcholinesterase and Butyrylcholinesterase inhibitory activities of $\beta$-carboline and quinoline alkaloids derivatives from the plants of genus peganum. Hindawi Publishing Corporation J Chem 2013;2013:1-6.

8. Helen MB, John W, Zukang F, Gary G, Bhat TN, Helge W, et al. The protein data bank. Nucleic Acids Res 2000;28:235-42.

9. Allgardsson A, Berg L, Akfur C, Hörnberg A, Worek F, Linusson $A$, et al. Structureof a prereaction complex between the nerve agent sarin, its biological target acetylcholinesterase, and the antidote HI-6. Proc Natl Acad Sci 2016;113:5514-9.

10. Carletti E, Schopfer LM, Colletier JP, Froment MT, Nachon F Weik $\mathrm{M}$, et al. Reaction of cresyl saligenin phosphate, the organophosphorus agent implicated in aerotoxic syndrome, with human cholinesterases: mechanistic studies employing kinetics, mass spectrometry, and X-ray structure analysis. Chem Res Toxicol 2011;24:797-808. 
11. Gajendran N, Aruldass I, Dhanapal S. In silico docking studies on the anti-cancer effect of thymoquinone on interaction with phosphatase and tensin homolog located on chromosome 10q23: a regulator of pi3k/akt pathway. Asian J Pharm Clin Res 2015;8:192-5.

12. Dallakyan S, Olson AJ. Small-molecule library screening by docking with PyRx. Methods Mol Biol 2015;1263:243-50.

13. Seeliger D, de Groot BL. Ligand docking and binding site analysis with PyMOL and Autodock/Vina. J Comput Aided Mol Des 2010;24:417-22.

14. Lipinski CA, Lombardo F, Dominy BW, Feeney PJ. Experimental and computational approaches to estimate solubility and permeability in drug discovery and development settings. Adv Drug Delivery Rev 2001;46:3-26.

15. Alexey $L$, Dmitrii $F$, Vladimir P. PASS: prediction of activity spectra for biologically active substances. Bioinformatics 2000;16:747-8.

16. Houghton PJ, Ren Y, Howes MJ. Acetylcholinesterase inhibitors from plants and fungi. Nat Prod Rep 2006;23:181-99.

17. Williams P, Sorribas A, Howes MJ. Natural Products as a source of Alzheimer's drugs leads. Nat Prod Rep 2011;28:48-77.

18. Mukherjee PK, Kumar V, Mal M, Houghton PJ. Acetylcholinesterase inhibitors from plants. Phytomedicine 2007;14:289-300.

19. Arkypova VN, Dzyadevych SV, Soldatkin AP, El'skaya AV, Martelet C, Jaffrezic-RN. Development and optimisation of biosensors based on ph-sensitive field effect transistors and cholinesterases for sensitive detection of solanaceous glycoalkaloids. Biosens Bioelectron 2003;18:1047-53.

20. Dzyadevich S, Arkhypova VN, Soldatkin AP, Elskaya AV Martelet C, Jaffrezic RN. Enzyme biosensor for tomatine detection in tomatoes. Anal Lett 2004;37:1611-24.

21. Benilova IV, Arkhypova VN, Dzyadeviych SV, Jaffrezic RN, Martelet C, Soldatkin AP. Kinetics of human and horse sera cholinesterases inhibition with solanaceous glycoalkaloids: study by potentiometric biosensor. Pestic Biochem Physiol 2006;86:203-10.

22. Miroslav Pohanka. Inhibitors of acetylcholinesterase and butyrylcholinesterase meet immunity. Int $\mathrm{J}$ Mol Sci 2014;15:9809-25.

23. Ekins S, Mestres J, Testa B. In silico pharmacology for drug discovery: methods for virtual ligand screening and profiling. Br J Pharmacol 2007;152:9-20.

24. Tracey B, Pedro C, Salim B, Richard G, Andrew JD, Jim W. Sites Identify: a protein functional site prediction tool. BMC Bioinformatics 2009;10:379-91.

\section{How to cite this article}

- $\quad$ Punabaka Jyothi, Kuna Yellamma. Molecular docking studies on the therapeutic targets of alzheimer disease (AChE and BChE) using natural bioactive alkaloids. Int J Pharm Pharm Sci 2016;8(12):108-112. 